\title{
LA MILITANCIA DE ABOGADOS EN DEFENSA DE LOS DERECHOS HUMANOS A PARTIR DE LA ÚLTIMA DICTADURA MILITAR EN ROSARIO. ANTECEDENTES, PARTICIPACIÓN Y PERTENENCIAS IDENTITARIAS
}

\author{
MARIANELA SCOCCO (UNR/ISHIR-Conicet) \\ Facultad de Humanidades y Artes / Instituto de Investigaciones Socio-históricas Regionales \\ Universidad Nacional de Rosario / Consejo Nacional de Investigaciones Científicas y Técnicas \\ marianob4@hotmail.com; mariascocco@mail.com
}

\begin{abstract}
Resumen
El eje de este artículo es el análisis de la militancia de abogados en defensa de los derechos humanos en la última dictadura militar (1976-1983) y en los primeros años de democracia. Sin embargo, el fundamento será colocado en las transformaciones en el perfil de los abogados que se dedicaron a esta tarea a través de un recorrido por el proceso que va de los primeros abogados que se abocaron a la defensa de los detenidos por razones políticas y/o gremiales desde mediados de la década de 1930, principalmente en la segunda mitad del siglo XX, hasta los años 1970 con la instauración de la última dictadura. El objetivo es estudiar a estos actores y los espacios asociativos de los que formaron parte, haciendo hincapié en la circulación de ellos en más de una organización, es decir, en su doble o múltiple pertenencia militante. Nos centraremos en el caso de la ciudad de Rosario, tomando como ejemplo a dos abogadas que se abocaron a la defensa de los derechos humanos con su participación en distintos organismos de la ciudad.
\end{abstract}

Palabras claves:

Abogados - Derechos Humanos - Participación

\begin{abstract}
This article focuses on the analysis of the lawyer's militancy in defending the human rights during the last dictatorship (1976-1983) and in the first years of democracy. However, we will focus on the changes of the lawyer's profile who had dedicated to this activity. We identify a process that started with the firsts lawyers who had defended the first detainees held for political and guild reasons since the mid 1930- specially the second half of the XX century- to the establishment of the last dictatorship, in 1970. The main objective is to study these social and political actors and the associations in which they had participated: we will analyze their circulation, it is to say, their double or multiple political membership. We will focus on the case of the city of Rosario and we will take as an example the case of two lawyers who had dedicated to the human rights defense by taking part in different organizations of the city.
\end{abstract}

Key words:

Lawyers - Human Rights -Participation 


\title{
LA MILITANCIA DE ABOGADOS EN DEFENSA DE LOS DERECHOS HUMANOS A PARTIR DE LA ÚLTIMA DICTADURA MILITAR EN ROSARIO. ANTECEDENTES, PARTICIPACIÓN Y PERTENENCIAS IDENTITARIAS
}

\author{
MARIANELA SCOCCO (UNR/ISHIR-Conicet) \\ maria nob4@hotmail.com; mariascocco@mail.com
}

\section{Introducción}

Aquello que durante la última dictadura militar (1976-1983) sería conocido como la defensa por los derechos humanos, en Argentina comenzó promediando la década de 1930 tras el primer golpe de Estado. Desde entonces asomaron como figuras destacadas quienes tomaron a su cargo la defensa de los presos por razones políticas y/o gremiales: los abogados. Pero las acciones de apoyo, solidaridad y defensa de detenidos políticos adquirieron mayor protagonismo en la segunda mitad del siglo XX. Como sostiene Chama, tras el golpe de Estado a Perón en 1955 se fue conformando un campo consagrado a la defensa de los presos políticos y gremiales. "De ese espacio participaron viejos y nuevos actores que desarrollaron relaciones de intercambio y cooperación, a pesar de su identificación con tradiciones políticas referenciadas tanto en la izquierda como en el peronismo". ${ }^{1}$

No obstante lo anterior, los profesionales del Derecho dedicados a tales tareas adquirieron mayor relevancia en los años de 1970, sobre todo a partir de la instauración de la última dictadura militar de 1976-1983.

En este artículo indagaremos sobre la intervención activa y decidida de estos abogados a través de todo el proceso y en las transformaciones que experimentaron.El objetivo es estudiar a estos actores y los espacios asociativos de los cuales formaron parte, haciendo hincapié en la circulación de ellos en más de una organización, es decir, en su doble o múltiple pertenencia militante.

Por otro lado, pese a que frecuentemente suele relacionarse la participación de los profesionales del Derecho en los organismos de derechos humanos a partir de la última dictadura como resultado exclusivo de la represión del Estado, consideramos que esta explicación es insuficiente para comprender la adhesión a tal causa, que supone un proceso más amplio. De esta forma exploraremos los motivos que incentivaron su participación, que se explican ademáspor lazos políticos, sociales y afectivos previos a la constitución de las organizaciones y por afinidades ideológicas preexistentes a la propia acción colectiva.

Nos centraremos en el caso de la ciudad de Rosario, tomando como ejemplo a dos abogadas que se abocaron a la defensa de los derechos humanos con su participación en distintos organismos de la ciudad. Indagaremos sobre sus contribuciones en estos organismos pero también sobre sus concepciones políticas y las pertenencias identitarias que definieron su integración en uno u otro, algunas veces de manera simultánea y otras alternativamente.En este sentido, consideramos que el análisis de sus biografías y sus trayectorias es una herramienta privilegiada para reconstruir ese proceso.

\footnotetext{
${ }^{1}$ Chama, Mauricio, "Activismo social, militancia política y radicalización en los años sesenta. La experiencia de la Comisión de Familiares y Detenidos (COFADE)”, en Tortti, María Cristina (dir.) La nueva izquierda argentina (19551976): socialismo, peronismo y revolución, Rosario, Prohistoria Ediciones, 2014, pág. 112.
} 


\section{Antecedentes en la defensa de presos políticos}

En Argentina, en el marco creado por el primer golpe de Estado de 1930, con un creciente número de presos políticos y el surgimiento de la "Sección Especial para la Represión del Comunismo", fue fundada el 20 de diciembre de 1937 la Liga Argentina por los Derechos del Hombre (LADH), el primer organismo dedicado exclusivamente a la defensa de los derechos humanos. Como sostiene Mauricio Chama; la LADH“(...) representaba el organismo con mayor trayectoria pública y grado de institucionalización en la asistencia jurídica y solidaridad con los presos políticos y sus familiares, así como también en la labor de denuncia contra procedimientos represivos estatales". ${ }^{2}$ Si bien la LADH había surgido bajo el impulso del Partido Comunista (PC), desde su formación buscó atraer intelectuales, profesionales y dirigentes políticos referenciados en distintas vertientes ideológicas. Sin embargo, hacia mediados de la década de 1950 su composición interna fue variando hasta perder su impronta pluralista y tener mayor notoriedad dirigentes provenientes del PC. A partir de 1955 nuevos actores se incorporaron a la defensa de presos políticos: los abogados peronistas.

A mediados de los años '60, además de la LADH, la Comisión de Familiares de Detenidos (Cofade) nucleó a abogados vinculados al peronismo. Según Chama, "Esta entidad, que a diferencia de la LADH funcionó con un grado mínimo de institucionalización, había sido concebida por un reducido grupo de familiares y militantes peronistas en el año 1960 en respuesta a la puesta en marcha del plan CONINTES ${ }^{3}$ por parte del gobierno de Frondizi”. ${ }^{4}$

Pero el grupo de abogados por entonces más activo en la defensa de presos gremiales y políticos se articuló en torno de la combativa Confederación General del Trabajo de los Argentinos (CGTA). Se denominó cuerpo de abogados de la CGTA. "Si bien la mayoría de los integrantes del cuerpo de abogados de la CGTA se definía políticamente como peronista, la incorporación del radical Hipólito Solari Yrigoyen o la del abogado de izquierda Néstor Martins expresaba el carácter plural y abierto de la central sindical opositora". 5

Siguiendo a Chama:

"Al tiempo que el descontento social fue en aumento (y, por ende, también los arrestos de activistas políticos y dirigentes gremiales) se volvió necesario para el cuerpo de abogados de la CGTA contar con la colaboración de otros profesionales radicados en ciudades del interior, dispuestos a presentar en tiempo y forma recursos de amparo y hábeas corpus en favor de los detenidos. El resultado de ello fue la constitución de filiales en distintos puntos del país dedicadas a la defensa de presos sociales y políticos, particularmente en aquellas ciudades donde la protesta social comenzaba a cobrar mayor intensidad como en Córdoba, Mar del Plata, Paraná, La Plata o Tucumán". 6

En la Capital Federal o en el Gran Buenos Aires los abogados vinculados a Cofade o a la LADH mantuvieron contactos frecuentes con la CGTA.

\footnotetext{
${ }^{2}$ Chama, Mauricio, “Activismo social, militancia política y radicalización...”, op. cit., pág. 112.

3 El Plan de Conmoción Interna del Estado (CONINTES) fue aprobado por el Decreto Secreto No 9.880 bajo la presidencia de Arturo Frondizi el 14 de noviembre de 1958 y se ejecutó entre el 13 de marzo de 1960 y el 1 de agosto de 1961. Era un plan de seguridad y militarización interna. Postulaba la creación de una serie de zonas y subzonas de defensa bajo autoridad militar en todo el país para la conducción de las acciones de represión interna. Establecía que las fuerzas policiales debían subordinarse operativamente durante la aplicación del Plan.

${ }^{4}$ Chama, Mauricio, Compromiso político y labor profesional. Estudios sobre psicólogos y abogados en los primeros setenta, La Plata, Universidad Nacional de La Plata. Facultad de Humanidades y Ciencias de la Educación, 2016, pág. 111.

${ }^{5}$ Chama, Mauricio, Compromiso político y labor profesional... op. cit., pág. 112.

${ }^{6}$ Chama, Mauricio, Compromiso politico y labor profesional... op. cit., pág. 112.
} 
En la ciudad de Rosario, la que tomaría mayor protagonismo sería la Agrupación de Abogados de Rosario (AAR), conformada en el año 1968 por un grupo de profesionales del Derecho de orientación ideológica de izquierda. Este grupo asumió la defensa de presos políticos, cualquiera fuera su pertenencia política o gremial, mientras perduró la dictadura (1968-1973). ${ }^{7}$

Ese mismo año, ocurrió en la provincia de Santa Fe lo que sería posteriormente conocida como la "Intervención Saráchaga". Los abogados Juan Carlos Gardella ${ }^{8}$ y Armando Frávega, en Rosario, y Juan García, en La Plata, habían amparado desde sus estratos judiciales la realización de dos actos los días 13 y 14 de junio de 1968 en conmemoración de los cincuenta años de la Reforma Universitaria, resoluciones amparadas por la Cámara Federal. En Rosario, pese a la autorización con la que contaban los estudiantes y a la presencia de ambos jueces en los respectivos actos, la policía los reprimió, impidiendo su realización. El juez Enrique Basualdo también había hecho lugar a otro amparo por un tercer acto que iban a realizar un grupo de abogados, pero había sido revocado por la Cámara de Apelaciones a último momento, en cambio los dos primeros habían sido confirmados por la misma Cámara. El 17 de junio Gardella y Frávega sancionaron con 15 días de arresto al Jefe de la Policía rosarina, el gendarme retirado Abel Vergaguer, y a los Comisarios Alfredo Bagli y Manuel Valdéz, por la desobediencia. El 18 de junio los estudiantes se movilizaron por el centro rosarino. La decisión del gabinete del Presidente Onganía fue declarar en comisión al Poder Judicial y dejar cesantes a los magistrados. La solidaridad con los magistrados se manifestó en la renuncia de funcionarios del Poder Judicial. Dejaron sus cargos jueces, procuradores, fiscales y secretarios. El 26 de junio asumió el interventor del Poder Judicial, Darío Saráchaga,que desde el mes de julio comenzó a anunciar nuevas designaciones. El Colegio de Abogados de Rosario repudió a la intervención. La AAR emitió un documento también en repudio a la intromisión de la justicia santafesina. ${ }^{9}$

De todas formas, las acciones por apoyo y solidaridad de detenidos políticos se intensificaron especialmente en el período 1969-1973, en función del crecimiento y transformación cualitativa de la represión durante la dictadura de la Revolución Argentina, sobre todo a partir de las grandes luchas que los trabajadores y estudiantes desarrollaron en las principales ciudades del interior del país en el año 1969, que han sido recordadas popularmente con el sufijo "azos". ${ }^{10}$

\footnotetext{
${ }^{7}$ Bereciartúa, Leticia, Abogados y defensas politicas 1968-1973, Tesina de Licenciatura, Universidad Nacional de Rosario, Mimeo, 2013.

8 Juan Carlos Gardella nació el 20 de enero de 1931. Se recibió de abogado en 1958 y cinco años después fue nombrado Juez de $1^{\circ}$ instancia en lo Civil y Comercial en los Tribunales rosarinos. Veinte años después fue cesanteado por la intervención Saráchaga y se dedicó a dictar clases en la Facultad de Derechos de la UNR. Nunca volvió al Poder Judicial. En 1974 fue perseguido y amenazado por aquel pedido de captura de los jefes de la Policía rosarina, por lo que se exilió en Alemania hasta el regreso de la democracia.

${ }_{9}^{9}$ Del Frade, Carlos, Delia, la abogada militante, Rosario, Editorial La Comuna, 2011.

${ }^{10}$ La más conocida fue la insurrección popular sucedida en la ciudad de Córdoba, el 29 y 30 de mayo de 1969, recordada como el "Cordobazo". Pero días antes en la ciudad de Rosario se había producido el Primer Rosariazo. La lucha generada por el movimiento estudiantil comenzó con una serie de acontecimientos desarrollados en las ciudades de Resistencia y Corrientes, tras la decisión del rector de aumentar en un $500 \%$ el valor del comedor universitario, medida que fue repudiada a través de una marcha que fue reprimida y en donde perdió la vida el estudiante Juan José Cabral. En Rosario, el 17 de mayo unos cuatrocientos estudiantes se reunieron frente al comedor estudiantil y repartieron algunos volantes e hicieron explotar algunas bombas de estruendo que merecieron la atención de la policía, que los reprimió enérgicamente. Allí perdió la vida el estudiante de Ciencias Económicas Andrés Bello, generándose automáticamente una importante movilización de repudio en amplios sectores de la sociedad. En la marcha del día 21, fue asesinado por la policía el obrero y estudiante Luis Norberto Blanco. La policía fue desbordada y, en la madrugada del 22, el Comandante en Jefe del Ejército Alejandro Agustín Lanusse ordenó la declaración de Zona de Emergencia bajo jurisdicción militar para Rosario y sus alrededores. El Segundo Rosariazo se produjo en setiembre de 1969. El día 8, los obreros de la Unión Ferroviaria pertenecientes a los talleres ferroviarios de Pérez y Villa Diego, realizaron un paro de brazos caídos por la suspensión del delegado administrativo Mario Horat, motivada por la adhesión a varios paros nacionales. A raíz de este hecho, se produjeron movilizaciones de trabajadores y estudiantes por varios días, a las que se agregaron barricadas, incendios localizados,
} 
En el año 1971, se crearon distintas agrupaciones de solidaridad y apoyo a los presos políticos con reconocidos vínculos con algunas organizaciones políticas-militares, como la Organización de Solidaridad con los Presos Políticos, Estudiantiles y Gremiales (OSPPEG),vinculada a las organizaciones políticas Vanguardia Comunista y al Partido Comunista Revolucionario (PCR); la Comisión de Familiares de Presos Políticos, Estudiantiles y Gremiales (COFAPPEG), ligada el Partido Revolucionario de los Trabajadores (PRT) y otras de orientación peronista.

En la ciudad de Rosario, en noviembre de ese año, se constituyó la Comisión de Apoyo a los Presos Políticos y Gremiales. Por su parte, la OSPPEG, constituida en la ciudad de Santa Fe el 10 de julio de 1971, ${ }^{11}$ llevó a cabo actividades de reclamo por los presos rosarinos, en colaboración con los familiares de esta ciudad. La misma situación fue plasmada por la Comisión de Familiares de Presos Políticos de Rosario.

Luciano Alonso sostiene que en la ciudad de Santa Fe y su zona de influencia,

"Se registraron actividades de la Organización de Solidaridad con los Presos Políticos Estudiantiles y Gremiales, el movimiento de similar denominación, una Comisión Peronista de Apoyo a los Presos Políticos, una Comisión de Familiares de Presos Políticos y la Liga Argentina por los Derechos del Hombre (LADH), pero también otras organizaciones políticas definidas dentro del marco de la izquierda católica, peronista o marxista tuvieron acciones descollantes en el ámbito de la defensa de los presos políticos y la denuncia de la represión, como el Movimiento Ateneísta, el Partido Popular Santafecino (agrupación dependiente del Partido Revolucionario de los Trabajadores, PRT) o el Partido Comunista Revolucionario (PCR). De esos agrupamientos, para 1975 solo habría persistido una Comisión de Familiares de Presos con muy escasa sino nula presencia pública, mientras algunos abogados de renombre y con amplia trayectoria en la defensa de detenidos, como el democristiano Alfredo Nogueras y el demoprogresista Ricardo Molinas, ya se habían visto obligados a exiliarse". ${ }^{12}$

No obstante, estas agrupaciones tuvieron poca o ninguna continuidad, ya que con el fin del gobierno dictatorial y con la liberación de los presos políticos en la amnistía de 1973 se habían diluido muchas de las demandas. Por ello, en los casos en que no desaparecieron, la persistencia de las organizaciones defensoras de los derechos humanos se tornó eventual y partidaria de algunos sectores, por lo menos hasta el año 1975, con el incremento de la represión por parte del Estado. Como afirma Alonso:

"La lógica de las representaciones dominantes en la primera mitad de la década de 1970 presentaba el problema de los derechos humanos como una cuestión sin importancia propia. Es notorio que ninguna de las denominaciones de las agrupaciones de la época anterior apareció la expresión, primando las nociones de solidaridad o lazos de familia con los detenidos en poder del enemigo". ${ }^{13}$

En Rosario, por el contrario de lo que sucede en otras ciudades del país, no sólo tuvieron escasa o nula permanencia estas agrupaciones sino también sus militantes, que no reaparecen en los años

ataques a instalaciones ferroviarias, comercios y bancos, que fueron nuevamente reprimidas por un enorme operativo policial, al que debió sumarse Gendarmería Nacional para proteger las propiedades ferroviarias.

11 Diario Nuevo Diario, Santa Fe, 11 de julio de 1971, citado en Alonso, Luciano, Luchas en plazas vacías de sueños.Movimiento de derechos humanos, orden local y acción antisistémica en Santa Fe, Rosario, Prohistoria Ediciones, 2011, pág. 84.

12 Alonso, Luciano, "Emergencia, auge y crisis del movimiento por los derechos humanos en Santa Fe, 1977-1989”, en El país del si me acuerdo. Los orígenes nacionales y transnacionales del movimiento de derechos bumanos en Argentina: De la dictadura a la transición, Red Latinoamericana de Historia Oral, Buenos Aires: Editorial Imago Mundi, 2014, pág. 18.

13 Alonso, Luciano, Luchas en plazas vacías de sueños..., op. cit., pág. 89. 
siguientes o cuya trayectoria es difícil de rastrear, ya que sólo continúa en algunos abogados de renombre y con amplia experiencia en la defensa de presos políticos.

Desde la masacre de Ezeiza en junio de 1973, y con la modificación del escenario político latinoamericano con el advenimiento de dictaduras militares, el crecimiento de la represión estatal y paraestatal y las acciones de la Triple $\mathrm{A}^{14}$ se comenzó a alertar sobre la necesidad de una convocatoria más amplia en materia de organización, denuncia y acción jurídica en derechos humanos.

En la provincia de Santa Fe y en Rosario particularmente, ya en 1975, el Ejército asumió la dirección de la lucha "antisubversiva", junto a las fuerzas policiales y penitenciarias de la provincia que fueron puestas bajo el "control operacional" del Comando del II Cuerpo de Ejército. Se intensificaron los "operativos rastrillos" en las zonas fabriles -especialmente en Villa Constitución y las localidades de la zona norte del cordón industrial que se extendía entre Rosario y Puerto General San Martín-, el control sobre la universidad y en general sobre el ámbito urbano y la detención de militantes populares.

Párrafo aparte merece lo ocurrido en ese año en la localidad de Villa Constitución, a $60 \mathrm{~km}$ de Rosario. El 20 de marzo de 1975 un operativo represivo conjunto de las policías provincial y federal y de la prefectura naval ordenado por el gobierno de María Estela Martínez de Perón ocupó la ciudad con patrulleros y carros de asalto apoyados por helicópteros, lanchas de prefectura y perros, además de las consabidas fuerzas parapoliciales. Una columna de un kilómetro y medio de automóviles y camiones, compuesta por policías provinciales, federales, matones de la derecha sindical peronista y asesinos ligados a la Triple A, entre otros, invadieron la ciudad. Aproximadamente 300 obreros fueron detenidos (entre ellos toda la comisión directiva de la Unión Obrera Metalúrgica, con la excepción de Luis Segovia, que logró escaparse), mientras la sede sindical era convertida en base operativa para la represión.

También ocurrieron algunos asesinatos de personalidades reconocidas, entre ellos los abogados Felipe Rodríguez Araya y Luis Eduardo Lescano, que fueron secuestrados por una patota paraestatal y asesinados el 30 de septiembre de 1975.

Pero fue con el golpe de Estado que el accionar represivo alcanzó niveles mucho mayores. A partir del 24 de marzo de 1976 se sistematizaron los secuestros clandestinos y miles de personas comenzaron a engrosar las listas de desaparecidos.

\section{Los abogados en la defensa de los derechos humanos en Rosario durante la última dictadura militar}

Lo novedoso y el agravante de la coyuntura de la última dictadura militar fue la implementación de un nuevo dispositivo represivo, donde los aprehendidos, en su gran mayoría, no habían sido detenidos sino desaparecidos, lo que implicaba además una ruptura sustancial con la juridicidad vigente hasta el momento y demostró muy rápidamente la necesidad de implementar nuevas estrategias en la demanda.

\footnotetext{
${ }^{14}$ En los casos en los que el Estado descentraliza la represión o la deja en manos de grupos con cierta autonomía estamos en presencia de lo paraestatal, es decir, cuando los grupos que ejercen la violencia operan por fuera de la estructura formal del Estado. Estudios recientes han identificados distintas organizaciones paraestatales que actuaron durante el período constitucional 1973-1976 y que exceden ampliamente a las más conocida Triple A. Para un abordaje más completo del tema ver: Merele, Hernán, "La "depuración" ideológica del peronismo en el partido de General Sarmiento (1973 - 1974). Una aproximación a partir del caso de Antonio “Tito" Deleroni.", Tesis de Maestría en Historia Contemporánea, Universidad Nacional de General Sarmiento, Mimeo, 2015.
} 
Así surgieron en la ciudad de Rosario lasagrupaciones de personas abocadas a la defensa de los derechos humanos. Primero se nuclearon en Familiares de Desaparecidos y Detenidos por Razones Políticas y Gremiales de Rosarioen el año 1977. A principios de 1978, la LADH de Rosario les cedió un lugar en una vieja casona que tenía como local, ubicada en la Cortada Ricardone $\mathrm{N}^{\circ}$ 58. La histórica experiencia de formación de comisiones de familiares y de asistencia, defensa y solidaridad para con los presos políticos impulsada por la LADH en otras ocasiones, propulsaba una vez más la organización de los familiares para reclamar de forma conjunta por sus seres queridos.

Al mismo tiempo, los actores de estas luchas se diferencian de las anteriores porque aquellas se inscribían como frentes de derechos humanos de organizaciones partidarias. En cambio, ante esta situación diferente, donde además los familiares no contaban con los canales institucionales para hacer el reclamo, emergió un reclamo nuevo, en tanto universal. Los derechos humanos ya no aparecían como un frente más de lucha, sino como el elemento principal.

En este sentido, podemos afirmar, siguiendo a Alonso, que la particularidad del momento en que se desarrollan las nuevas estrategias de los organismos en defensa de los derechos humanos responde a

“(...) dos dimensiones de importancia: por un lado el régimen de violencia aplicado en Argentina para la represión y el exterminio de los opositores, que produjo un vacío en el cual se instalaron las nuevas agrupaciones, y por otro las peculiaridades de una combinación compleja de capacidades que se ensamblaron en las actitudes reactivas frente a ese régimen de violencia". ${ }^{15}$

Al mismo tiempo, la nueva coyuntura redefinió la retórica propia de la izquierda, que fue progresivamente desplazada hasta que el discurso por la defensa de los derechos humanos se convirtió en único y excluyente. ${ }^{16}$

En Rosario, en esta nueva coyuntura, la escasa continuidad de organizaciones y militantes contrastó con la participación de algunos abogados de notoriedad y con amplia trayectoria en la defensa de presos políticos, que asumieron un compromiso militante con la denuncia judicial y pública de las violaciones a los derechos humanos y la defensa y solidaridad con los compañeros detenidos.

Como sostiene Vecchioli: "El propio ejercicio de la profesión también actuó como espacio de relación y aproximación, ya que era frecuente el cruzarse en las visitas a los presos, organizar la búsqueda de los detenidos por comisarías, combinar con otros colegas la mejor estrategia jurídica" ${ }^{17}$ entre otras cosas. La participación y el encuentro en estas circunstancias fue creando intereses comunes, que se sumaron a las ideologías preexistentes y se cristalizaron en una causa común: la defensa de los derechos humanos.

Entre ellos, se destacaban aquellos abogados pertenecientes al Departamento Jurídico de la LADH Rosario, integrado por Adolfo Trumper, Ana María Figueroa, Ignacio Imbern, Manuel F. Blanco y Marta López. ${ }^{18}$

\footnotetext{
15 Alonso, Luciano, "Emergencia, auge y crisis del movimiento por los derechos humanos en Santa Fe, 1977-1989", op. cit., pág. 73 .

${ }^{16}$ Vecchioli, Virginia, "Derechos Humanos y compromiso militante. Un recorrido por la constitución de esta causa a través de los profesionales del derecho”, Etnografías Contemporáneas 2 (3), 2007, págs. 143-168.

17 Vecchioli, Virginia, “Derechos Humanos y compromiso militante...”,op. cit., págs. 148.

18 Ignacio Imbern y Marta López fueron muy reconocidos, entre otras cosas, por su defensa de los presos del "Villazo". Imbern, además, junto al pastor metodista Néstor Míguez, son recordados como los responsables de los contactos políticos para la constitución de la Asamblea Permanente por los Derechos Humanos (APDH) en Rosario.
} 
Pero también sobresalieron otros profesionales del derecho. La más conocida fue la abogada Delia Rodríguez Araya. Había sido una de las protestantes contra la Intervención Sarráchaga de 1968, cuando renunció a su cargo de fiscal. Fue una de las fundadoras de la filial local de la Asamblea Permanente por los Derechos Humanos (APDH) en el año 1979, participó como abogada de Familiares y también colaboró con Madres y Abuelas de Plaza de Mayo y con el Movimiento Ecuménico por los Derechos Humanos (MEDH) cuando fundaron sus delegaciones en la ciudad.

Otra destacada abogada que trabajó complementariamente en varios organismos de derechos humanos de Rosario, aunque de una generación posterior a la de Delia, fue Inés Cozzi. Si bien con militancia anterior al golpe de Estado de 1976, Cozzi obtuvo su título en ese año y desde entonces comenzó a trabajar por la defensa de los presos políticos, la búsqueda de los desaparecidos y el apoyo a los familiares. Se incorporó más tardíamente a la APDH, para colaborar también con Madres y Abuelas de Plaza de Mayo y, posteriormente, con el MEDH a sugerencia de Delia precisamente.

Un estudio biográfico comparado de las trayectorias de estas dos abogadas especializadas en la defensa de los derechos humanos en Rosario, con el propósito de identificar concurrencias y divergencias en las condiciones de su consolidación profesional, permite cuestionar aquellas distinciones tajantes entre unos organismos y otros, ya que ambas intervinieron activamente en más de uno e incluso simultáneamente.

Para tal objetivo llevaremos a cabo dos líneas de exploración; por un lado, una centrada en el análisis de las trayectorias profesionales y militantes de estas abogadas y, por otro, un examen de sus modos de incorporación en los organismos de derechos humanos locales. La multiplicidad de lugares ocupados por estas abogadas, los recursos que movilizaron y las circunstancias de entrada y permanencia al espacio de los organismosson parte de las condiciones de posibilidad y perdurabilidad de su compromiso militante.

La reconstrucción de estas carreras militantes apunta a comprender la serie de relaciones a las que pertenecieron y nutrieron con su participación.

\section{La experiencia puesta al servicio de la nueva coyuntura. Delia Rodríguez Araya}

Delia María Rodríguez Araya nació el 22 de mayo de 1929. Estudió Derecho en la Universidad Nacional del Litoral, concursó e ingresó como fiscal en el Poder Judicial de la Provincia de Santa Fe, donde renunció en junio de 1968 con la denominada Intervención Saráchaga. Participó en la defensa de presos políticos desde entonces con el incremento de la represión.

Con la última dictadura los pedidos de defensa se multiplicaron. A principios de 1978, por solicitud de la Embajada de Cuba, Delia asumió la defensa de Juan Martín Guevara, militante del PRT y hermano del Che, detenido desde marzo de 1975. Al hablar de aquel hecho Delia recordaba:

"Me preguntó [el embajador cubano] cuántos eran mis honorarios y le dije que nada. Me preguntó por qué nada, y le dije 'porque ustedes no pueden pagarme lo que significa esto', porque eso podía significar que te mataran a la vuelta o a la ida. Yo no iba a aceptar. Nada es nada, y eso no se paga con nada. ¿Con qué se paga eso?”."19

A diferencia de lo ocurrido en momentos previos y con otros casos, donde las gratificaciones simbólicas eran muy importantes, ya que el nombre del defendido enaltecía al abogado, ${ }^{20}$ para el

\footnotetext{
${ }^{19}$ Grabación de Delia, citada en Del Frade Carlos, Delia, la abogada militante, op. cit., pág. 79.

${ }^{20}$ Vecchioli, Virginia, "Derechos Humanos y compromiso militante...”, op. cit.
} 
año 1978 la represión había tomado tales dimensiones que ya eran pocos los profesionales del Derecho dispuestos a asumir estas defensas, con los riegos que implicaban. Además, para una abogada de una ciudad intermedia en cuanto a su tamaño como era Rosario, esas gratificaciones eran prácticamente nulas, aún con anterioridad a la última dictadura. Por lo que inferimos que la asunción de la defensa de Juan Martín Guevara por Delia Rodríguez Araya sólo se explica por su adhesión a la causa de la defensa de los derechos humanos.

A partir de esos casos, Delia se contactó con los familiares de detenidos y desaparecidos, que estaban comenzando a agruparse para unificar sus demandas. Carlos de la Torre, ${ }^{21}$ quien fuera uno de los fundadores de la APDH local junto a Delia, lo recordaba así:

"Con Delia empezamos a reunirnos alrededor del año '78 o '79. (...) Después vino la fundación de la ADPH en Rosario. Delia y yo fuimos unos de sus fundadores. Al acto formal de firmar un acta lo hicimos en Presidente Roca al 500, que era el estudio jurídico del Doctor López, a quien yo conocía del SINTER. (...) De todas maneras, desde antes de la fundación, hacía tiempo que nos veníamos reuniendo con Delia. Creo haberla visto por primera vez en el año 1977. Recuerdo que había una reunión en el Hotel Majestic en la que se iba a tratar la formación de una entidad de derechos humanos. Algunos compañeros que llegaron antes del horario establecido fueron detenidos. Junto a Delia, Fidel Toniolli ${ }^{22}$ y otros compañeros estuvimos haciendo gestiones para liberarlos. La convocatoria que se había hecho era amplia. Participaban organizaciones políticas y sociales. A mí me habían invitado como Secretario de CTERA. Yo era Secretario Adjunto de Bravo. En esa ocasión sacamos rápidamente a las personas detenidas, pero todo el movimiento quedó prontuariado". 23

Por entonces Delia también era la abogada de Familiares de Detenidos y Desaparecidos por Razones Políticas y Gremiales de Rosario, aún antes de la constitución de la filial de la APDH. Ésta se llevó a cabo en noviembre de 1979. Deliacomenzó a colaborar con la APDH hasta convertirse en una de sus principales referentes.En 1980, se dispuso un área de asesoramiento jurídico para los familiares de detenidos y desaparecidos en su nuevo local de calle Presidente Roca 532 y se realizó una convocatoria pública para incorporarinteresados, la cual fue notificada a través de un comunicado de prensa. ${ }^{24}$ De la asesoría letrada se encargaba la Comisión Jurídica, a cargo de la abogada Delia Rodríguez Araya.

Gracias a esa pertenencia y a toda su experiencia acumulada, en 1984 Delia participó de la Comisión Nacional sobre Desaparición de Personas (CONADEP), aunque en principio tuvo dudas sobre su constitución, en consonancia con las Madres de Plaza de Mayo. ${ }^{25}$ Olga Cabrera Hansen $^{26}$ afirma que Delia “(...) en un primer momento no estuvo de acuerdo con la

${ }^{21}$ Integró la primera junta ejecutiva de Confederación de Trabajadores de la Educación de la República Argentina (CTERA) en 1973, miembro del Sindicato de Trabajadores de la Educación de Rosario (SINTER) y fundador Asociación del Magisterio de Santa Fe (AMSAFE). Falleció el 26 de agosto de 2012.

${ }^{22}$ Fidel Toniolli, padre de Eduardo Toniolli, desaparecido el 9 de febrero de 1977, fue el Presidente y fundador de Familiares de Detenidos y Desaparecidos por Razones Políticas y Gremiales de Rosario, secretario de la Liga Argentina por los Derechos del Hombre (filial Rosario) y miembro de la Conadep. Falleció el 13 de octubre de 2002.

${ }^{23}$ Del Frade, Carlos, Delia, la abogada militante, op. cit., pág. 79.

${ }^{24}$ Comunicado de Prensa, febrero de 1980. Archivo de la APDH Rosario, gentileza de Norma Ríos.

${ }^{25}$ Las Madres proponían la conformación de comisiones legislativas con poderes especiales, tanto en el plano nacional como en las distintas provincias. Otros organismos, sobre todo la APDH, fueron miembros integrantes de la CONADEP.

${ }^{26}$ Reconocida abogada, participó de la Agrupación de Abogados de Rosario (AAR) desde 1968, comprometiéndose muy tempranamente con la defensa de los presos políticos, lo que le costó que le pusieranuna bomba en su estudio y domicilio antes del 24 de marzo de 1976. A fines de ese año fue secuestrada y trasladada al SI, para ser liberada en 1978. Desde entonces comenzó a trabajar con los organismos de derechos humanos. Cabrera Hansen integró la CONADEP y escribió el capítulo del Nunca Más dedicado a la provincia. Véase Tessa, Sonia "Esto tiene que 
CONADEP. Pero allí estaba un tipo fenomenal, como era Fidel Toniolli". ${ }^{27}$ Alicia Lesgart, integrante de Familiares Rosario, recuerda: "El trabajo de investigación, testimonios, denuncias, se fue haciendo (...) Cuando se constituye la CONADEP en Rosario, el trabajo ya estaba hecho. Delia elabora el informe y lo entrega" ${ }^{28}$ Todo ese trabajo fue fundamental además en el armado de la comúnmente conocida "Causa Feced"29 dedicada a la represión en el área de Rosario, luego del Juicio a las Juntas Militares.

Una de las tareas más importantes para la investigación de la CONADEP fueron los allanamientos que se realizaron en departamentos céntricos denunciados como lugares de ocultamiento de archivos de los servicios de inteligencia del Ejército y la Policía. Se efectuaban con participación de la Justicia ya que al tratarse de domicilios particulares era necesaria una orden judicial..$^{30}$ En todos los casos se habían tomado precauciones para evitar que la información sobre los allanamientos se filtrara. Al respecto De la Torre rememoraba:

"Con ella [Delia] fuimos a los primeros allanamientos. Por una cuestión de seguridad, habíamos acordado con el Juez Fermoselle que a los allanamientos los íbamos a hacer sabiendo sólo nosotros a dónde íbamos, y que recién al subir al auto oficial él sería informado. Recuerdo que teníamos como estrategia dar muchísimas vueltas hasta llegar al lugar que correspondía. En una oportunidad Delia dijo: 'Siempre nos sigue el mismo auto'. Mientras nos manejábamos con el criterio de ser sólo nosotros quienes sabíamos a qué ligar íbamos, nunca falló ningún allanamiento. La cosa cambió totalmente con el robo a Tribunales. ${ }^{31}$ El juez Navarro nos dijo que él no podía hacer eso porque tenía a su cargo la fuerza del orden y que en segundo lugar la tenía la policía. A partir de esto, ningún allanamiento resultó". 32

Paradójicamente, fue en ese contexto de transición democrática cuando llegaron los mayores temores por las sucesivas intimidaciones, que no habían tenido tanta trascendencia aún en plena dictadura militar. Delia, en una entrevista, lo manifestaba así: "Vos me preguntaste si yo tuve miedo. Con lo de Martín [Guevara] no, pero con los allanamientos de la CONADEP, sí". ${ }^{33} \mathrm{Y}$ otra militante de derechos humanos, Graciela Ramírez, afirma que “(...) luego del robo a Tribunales de Rosario, Delia fue amenazada seriamente. Tuvo que hacer su propio exilio, alejándose unos años de Rosario y radicándose en el Sur". ${ }^{34}$

Delia es un claro ejemplo de aquellos militantes que pertenecieron a más de una organización.También intervino en la formación y desarrollo del MEDH en Rosario con asesoramiento jurídico y, paralelamente, en las asociaciones de Madres y Abuelas de Plaza de Mayo en Rosario. Inés Cozzi recuerda: "También pusimos todo nuestro esfuerzo en acompañar la formación de Madres de Plaza de Mayo en Rosario, a la que Delia también acompañó y

terminar de una vez", diario Rosario 12, Rosario, 30 de noviembre de 2010 y Basso Juane, "Juicio Díaz Bessone: La violación de detenidas fue una práctica sistemática", El diario de los Juicios, Rosario, disponible en http://www.diariodelosjuicios.com/2010/11/juicio-diaz-bessone-la-violacion-de.html.

27 Del Frade, Carlos, Delia, la abogada militante, op. cit., pág. 182.

${ }^{28}$ Del Frade, Carlos, Delia, la abogada militante, op. cit., pág. 20.

${ }^{29}$ Causa Federal 47.913. Centro Documental "Rubén Naranjo", Museo de la Memoria de Rosario.

30 Scocco, Marianela, "De la denuncia a la (in)justicia. Rosario: de la delegación Santa Fe de la CONADEP a los indultos (1983-1990)", Revista Argirópolis, no 1, Instituto de Estudios Históricos del Parlamento Argentino, segundo semestre, 2015, págs. 39-60.

31 En la madrugada del 8 de octubre de 1984, un grupo numeroso de personas, algunas con uniformes policiales, asaltaron las oficinas judiciales y se llevaron todos los comprobantes y expedientes que tramitaba el juez Fermoselle según procedimientos consignados por la Conadep. También robaron gran cantidad de armamento que había sido incautado durante la investigación. Véase Scocco, Marianela, "De la denuncia a la (in)justicia...", op. cit.

32 Del Frade, Carlos, Delia, la abogada militante, op. cit., pág. 148.

${ }_{33}$ Grabación de Delia, citada en Del Frade, Carlos, Delia, la abogada militante, op. cit., pág. 81.

${ }^{34}$ Del Frade Carlos, Delia, la abogada militante, op. cit., pág. 109. 
potenció, ya que estaba muy unida afectivamente a las Madres de Rosario". ${ }^{35}$ Pero al poco tiempo de la constitución de estas organizaciones ${ }^{36}$ Delia tomó la decisión de trasladarse al sur, en parte por las amenazas recibidas.

El 26 de agosto de 1986 fue nombrada Juez de la Cámara Federal de Apelaciones de Comodoro Rivadavia. Investigó los hechos cometidos en el Regimiento 8 de Infantería "General O'Higgins" durante los primeros tiempos de la dictadura, pero fue separada de la causa en febrero de 1987 por su participación en la CONADEP. En septiembre de ese año ocurrió un atentado contra los integrantes de la Cámara Federal de Comodoro Rivadavia, entre los que se encontraba Delia. Quedó afuera de todos los casos donde se juzgaban militares. Once años después de haber asumido en Comodoro Rivadavia, el 30 de diciembre de 1997, Delia presentó su renuncia a la Justicia Federal chubutense y volvió a Rosario.

El 19 de diciembre de 2003, Familiares de Detenidos y Desaparecidos, Madres de Plaza 25 de Mayo, Abuelas de Plaza de Mayo, el MEDH e HIJOS de Rosario auspiciaron y promovieron el proyecto de la entonces concejala Patricia Lagarrigue para declarar a Delia Ciudadana Ilustre.

\section{E1 compromiso de la juventud. Inés Cozzi}

Inés Cozzi es oriunda de la ciudad de San Lorenzo, a 25 kilómetros de Rosario, bordeando el cordón industrial delas localidades de la zona norte. Empezó a estudiar Derecho en la Universidad Nacional de Rosario en 1970. Casi inmediatamente comenzó a participar en el Partido Socialista de los Trabajadores (PST) y para las elecciones del año 1973 militó concretamente para la lista del PST. Después participó en la Juventud Socialista (JS) del PST, del '73 en adelante:

"Yo militaba en la JS del Partido Socialista de los Trabajadores y estudiaba Derecho (en ese orden). Vivía en San Lorenzo, donde daba clases particulares para costear mis estudios, y viajaba todos los días a Rosario. Conocía muy bien lo que estaba pasando en el cordón industrial norte". ${ }^{37}$

En el año 1975, después de la declaración del Estado de Sitio, el PST pasó a la clandestinidad y se empezaron a aplicar las leyes represivas. Comenzaron las detenciones masivas, sobre todo en el movimiento obrero. En ese contexto, Inés se recibió de abogada el 20 de marzo del 1976. Desde ese momento comenzó a trabajar por los presos políticos:

“(...) se me ofrece integrar un grupo para trabajar en apoyo de las causas judiciales, que el abogado del partido era un viejo militante socialista, Luis Broquen, que estaba en Buenos Aires. Él era una institución en los organismos de derechos humanos, un hombre grande tenía casi 80 años, y bueno como no se podía firmar, él llevaba todas las causas, no sólo de compañeros nuestros sino de otras organizaciones, pero necesitaba gente que le hiciera un poco la Procuración acá en Rosario y Santa Fe, bueno, y yo acepté". ${ }^{38}$

Esa tarea de defensa y denuncia jurídica fue combinada además con la tarea militante de asistencia y acompañamiento a los familiares.

\footnotetext{
35 Del Frade Carlos, Delia, la abogada militante, op. cit., pág. 94.

36 Sobre la constitución de Madres y Abuela de Plaza de Mayo de Rosario, véase Scocco, Marianela, El viento sigue soplando. Los orígenes de Madres de Plaza 25 de Mayo de Rosario (1977-1985), Rosario, Editorial Último Recurso, 2016. Sobre la constitución del MEDH Regional Rosario, véase Lezcano, Erika, “Testigos, protagonistas y redes sociales en el proceso de surgimiento y consolidación de la Regional Rosario del Movimiento Ecuménico por los Derechos Humanos (MEDH). Primera mitad de los años '80", Seminario Regional, en Historia, Facultad de Humanidades y Artes, Universidad Nacional de Rosario, Mimeo, 2015.

${ }^{37}$ Del Frade, Carlos, Delia, la abogada militante, op. cit., pág. 92.

${ }^{38}$ Inés Cozzi. Entrevista realizada el 25 de febrero de 2016 en la Rosario.
} 
Por el año 1977 aproximadamente, Inés comenzó a participar en un lugar que se llamaba Instituto de Estudios Nacionales (IEN), por invitación de otro reconocido abogado, Oscar Borgonovo. " “(...) él decía que había que armar pequeños lugares de investigación, de estudios, que fueran como pequeños focos de resistencia, y yo participaba en eso".$^{40}$ Allí conoció a algunos compañeros con los cuales luego militaría en los organismos de derechos humanos, entre ellos al agrimensor Juan Alberto Montes. ${ }^{41}$

Cozzi ya había sido arrestada varias veces "piqueteando" - como dice ella- en las fábricas del cordón industrial: dos veces en la puerta de Duperial y una en la de Petroquímica; pero en 1980 fue detenida junto a otros compañeros del PST.

"Cae un compañero que era trabajador y a partir de ahí empiezan a buscar, van a allanar la casa de mis viejos en San Lorenzo, van al estudio donde yo trabajaba y encuentran un recibo de alquiler donde yo vivía y caen y me detiene a mí y a mi marido. A mí me tienen clandestina un tiempo y después me legalizan porque interviene el Colegio de Abogados.Mi familia lo contrata a Bernardo Iturraspe, ${ }^{42}$ que era otra institución". ${ }^{33}$

Con su detención la dejaron cesante en el cargo que había concursado en el año 1977 en la Dirección de Niñez de la provincia de Santa Fe. Permaneció poco tiempo detenida y luego fue liberada, otorgándole la absolución provisoria recién el año 1982 y la definitiva ya en democracia.

Si bien ya había participado de algunas de sus actividades como cenas y homenajes, fue después de su liberación que se acercó a los organismos de los derechos humanos que se habían conformado en la ciudad, para aportar de una manera más amplia en su defensa: “(...) fue bastante tiempo después, en las cercanías de la democracia, que me acerqué con otros jóvenes a los organismo de derechos humanos, más concretamente a la APDH y Familiares que funcionaban en conjunto en calle Corrientes". ${ }^{44}$ Aunque Cozzi nunca se consideró una víctima, en ella se unía la doble condición de militante represaliada y profesional del derecho.

"Después de mi detención, dentro del Instituto, ya en el año '82 más o menos, Montes empieza a invitar gente porque bueno él dice que ya después de lo de Malvinas se veía que el gobierno ya no se sostenía más... Entonces empieza a invitar gente (...) era un grupo que se reunía y en una oportunidad uno de ellos me propone acercarme a la APDH y a Familiares que ya estaban funcionando y que había una especia de grupo de apoyo en la APDH de jóvenes. Y bueno ahí yo me integro primero al grupo de apoyo de jóvenes en la APDH" ${ }^{45}$

Para ese entonces Familiares y la APDH trabajan en conjunto en un local de calle Corrientes, que había sido alquilado por la APDH y donde le habían cedido un espacio a Familiares.

'Ya estaban juntos en la calle Corrientes. Ya estaban ahí. Pero nosotros vamos como grupo de apoyo, ya había mucha gente joven que con la apertura empieza a ir. (...) Y estaba Delia. Entonces empezamos a trabajar con ella en la parte legal, que nos mandó a estudiar el

\footnotetext{
39 Oscar Borgonovo también participó en la organización para la conformación de la filial Rosario de la APDH.

40 Inés Cozzi. Entrevista realizada el 25 de febrero de 2016 en la Rosario.

${ }^{41}$ En 1973 fue Rector de la Universidad Tecnológica Nacional de Rosario (UTN) primero y de Buenos Aires más tarde. Su hijo Roald, fue muerto en enfrentamiento contra el Ejército Argentino durante la llamada Batalla de La Plata, el 22 de noviembre de 1976. Participó del Instituto de Estudios Nacionales y de la APDH Rosario. Falleció el 30 de junio de 1986. La biblioteca de la Facultad de Urbanismo de la Universidad de Rosario lleva su nombre.

42 Reconocido abogado, graduado en 1942 en la Universidad Nacional del Litoral, fue ministro de la Corte Suprema de Justicia santafesina (1988/91), convencional constituyente (1994), candidato a gobernador, profesor universitario, miembro del Colegio de Abogados. Falleció el 17 de agosto de 2006.

43 Inés Cozzi. Entrevista realizada el 25 de febrero de 2016 en Rosario.

${ }^{44}$ Del Frade, Carlos, Delia, la abogada militante, op. cit., pág. 92-93.

45 Inés Cozzi. Entrevista realizada el 25 de febrero de 2016 en Rosario.
} 
Código de Justicia Militar, porque al principio... eso también se le debe a Alfonsín; que se pasa de la Justicia Militar a la civil". ${ }^{46}$

Es en este momento de la historia que se vuelve complicado distinguir las actividades y los integrantes de ambos organismos. Según Inés, cada uno conservaba una Comisión Directiva que tomaba las decisiones, pero complementariamente la APDH realizaba "reuniones ampliadas" de las que participaban todos los organismos. ${ }^{47}$ Ana Moro, ${ }^{48}$ integrante de Familiares, recuerda:

"Familiares, junto a APDH, comienzan a trabajar para enjuiciar a los genocidas y se crea una Comisión de Acción Jurídica a cargo de la Dra. Delia Rodríguez Araya, integrada por miembros de ambos organismos. (...) Se realizan además las primeras conferencias de prensa denunciando el Centro de Detención Clandestino 'Servicio de Informaciones' y a los represores". ${ }^{49}$

Tras algunas discusiones al interior de Familiares, algunos de sus miembros comenzaron a participar directamente de la APDH. También se incorporaron ex presos políticos que habían salido en libertad recientemente. Tal es el caso, por ejemplo, de la propia Inés o de Ana Moro, en su doble condición de familiar de desaparecidos y ex presa política. Favorecida con este grupo, en el local en las calles Corrientes y Córdoba se organizó una resistencia muy activa, entre otras se destaca la actividad sobre la implementación de las pancartas con las fotos de los desparecidos que ya venían haciendo los familiares.

Ya en democracia, algunas madres de desaparecidos que integraban Familiares empiezan a hablar de la necesidad de la formación de Madres como filial de la organización de Buenos Aires. "Entones del grupo este de apoyo hay un grupo grande que empieza a militar por la formación de Madres" ${ }^{50}$, sostiene Inés.

"Se decide [la formación de Madres] y empiezan a funcionar temporariamente en el IRDES, ${ }^{51}$ que era del PCR, y después se alquila un local en la calle Montevideo 1220. Pero bueno fue una ruptura bastante importante, sobre todo porque las Madres en ese momento estaban en contra de la CONADEP, porque ellas decían bueno se va a crear una comisión, se van a armar legajos y ahí se cierra todo, con esta consigna famosa; se los llevaron con vida, devuélvanlos o dígannos dónde está el cuerpo. Bueno y ahí casi toda la juventud se va con las Madres". 52

De esta forma, Inés no colabora con la CONADEP, a diferencia de DeliaRodríguez Araya, que fue incluso integrante de la Comisión local. Rodríguez Araya se había quedado trabajando en el local de calle Corrientes, como integrante de APDH pero también como abogada de Familiares. Esto último, así como su participación en la CONADEP, no le impidió conservar una estrecha relación con las Madres. Inés afirma:

"Delia consideraba -tal vez con razón- que todo era necesario. Porque después lo que fue el archivo de la CONADEP permitió la reapertura de los juicios, en realidad todo sirvió. No es que la Comisión investigara, en realidad todo el trabajo de investigación, que es lo

\footnotetext{
${ }^{46}$ Inés Cozzi. Entrevista realizada el 25 de febrero de 2016 en Rosario.

47 Estas reuniones continuaron en los años ' 80 y cuando ya se habían formado otros organismos como Madres y Abuelas de Plaza de Mayo y el MEDH sus integrantes participaban de ellas.

48 Ana Moro, ex presa política y militante histórica en derechos humanos, integró el grupo de Familiares de Detenidos y Desaparecidos por Razones Políticas y Gremiales de Rosario desde sus orígenes. Hermana de Miriam Moro, desaparecida y asesinada el 27 de septiembre de 1976.

49 Del Frade, Carlos, Delia, la abogada militante, op. cit., pág. 157.

50 Inés Cozzi. Entrevista realizada el 25 de febrero de 2016 en Rosario.

51 Instituto Rosarino de Estudios Sicosocial, actualmente Escuela de Psicología Social de Rosario, Instituto "Dr. Enrique Pichon Riviére".

52 Inés Cozzi. Entrevista realizada el 25 de febrero de 2016 en Rosario.
} 
mismo que ocurre en los juicos ahora, lo habían hecho los organismos. La comisión recopiló. Visto desde 'el ahora' me parece que es bueno que exista un archivo porque eso permite reconstruir mucho más rápido las líneas de investigación hacia los represores, pero bueno en ese momento que era todo tan cercano parecía más político exigir la apertura de los archivos y que dijeran qué había pasado (...) Delia era una persona que todos veíamos como referente y tampoco era una discusión para partirse. Incluso ella participaba en todas las actividades de Madres, Delia era así, ella participó en todas las actividades de Madres". ${ }^{3}$

Por entonces también se constituyó la Regional del MEDH en Rosariocon mucha influencia de la Iglesia Evangélica Metodista, aunque la principal iniciativa provenía del reconocido cura Santiago Mac Guire ${ }^{54}$. Delia intervino en la formación y desarrollo del $\mathrm{MEDH}$ en Rosario con asesoramiento jurídico, pero por entonces decidió aceptar el cargo de camarista que le habían ofrecido en Comodoro Rivadavia, y sugirió a Inés Cozzi para que continúe esa tarea.

"Las organizaciones de las Iglesias Metodistas le ofrecen a Santiago Mac Guire constituir acá el MEDH, que antes no funcionaba, entonces tenían un local en la esquina de Tribunales, Balcarce me parece. Fue después de la CONADEP, porque un día me llama Delia y me dice: 'Mira me ofrecen a mi ser abogada pero yo me voy, quiero que seas vos', porque me quedé un tiempo en el estudio de ella. Y entonces bueno, yo a Santiago ya lo conocía y bueno, encima digo yo, yo no soy creyente... ahí que Santiago me dice: 'Vos sos más cristiana que muchas cristianas' (risas). Y ya entonces se forma y yo empiezo a trabajar también en el MEDH en la parte jurídica". ${ }^{55}$

Con el MEDH sucedió algo similar que con la APDH en la participación de la CONADEP, ya que uno de los principales referentes de la Iglesia Metodista e impulsores del MEDH, Hugo Urcola $^{56}$, integró la Comisión local. Pero eso tampoco afectó las relaciones con los organismos y/o los militantes que se oponían a aquella, especialmente las Madres. Inés describe que:

"Santiago Mac White tenía una relación con las Madres muy, muy buena. O sea que Santiago se la pasaba en el local de las Madres. Era así, Santiago era como Delia, las Madres lo adoraban. Los hijos estaban en la comisión de apoyo a las Madres, estaba Lucas Mac Guire. Los chicos estaban ahí. El MEDH sí participó de la CONADEP, me parece que estaba en formación el MEDH, yo participé después". ${ }^{57}$

Por último, Inés también trabajó en la filial de Rosario de Abuelas de Plaza de Mayo, a pedido de su presidenta, Darwinia Gallicchio. "Paralelamente, [al llamado del MEDH] la Darwi me ofrece

\footnotetext{
53 Inés Cozzi. Entrevista realizada el 25 de febrero de 2016 en Rosario.

${ }^{54}$ Santiago Mac Guire falleció el 5 de julio de 2001. Fue teólogo y filósofo, estudió lenguas clásicas y además fue una personalidad destacada en Rosario. Fue integrante del Movimiento de Sacerdotes para el Tercer Mundo (MSTM) y uno de los curas "renunciantes", pues, al haber adherido a los postulados del Concilio Vaticano II y al Manifiesto de los 18 obispos del Tercer Mundo se posicionó en las antípodas del arzobispado rosarino, razón por la cual él y su grupo fueron excluidos de la diócesis local por iniciativa del arzobispo Guillermo Bolatti. Monseñor Bolatti se oponía a la aplicación de esa línea de acción dentro del territorio bajo su autoridad. Fue el primer coordinador de la Regional Rosario del MEDH y también participó en actividades de APDH Delegación Rosario. Véase Lezcano, Erika, "Testigos, protagonistas y redes sociales...", op. cit.

${ }^{55}$ Inés Cozzi. Entrevista realizada el 25 de febrero de 2016 en Rosario.

56 Es obispo de la Iglesia Metodista Argentina, estuvo fuertemente involucrado en movimientos de derechos humanos, participó de la fundación del MEDH Rosario e integró la delegación Santa Fe de la CONADEP.

57 Inés Cozzi. Entrevista realizada el 25 de febrero de 2016 en Rosario.

58 Darwinia Gallicchio, madre de Stella Maris Gallicchio, desaparecida el 5 de febrero de 1977 junto a su hija Ximena Vicario de 9 meses de edad. El mismo día fue secuestrado su yerno, el padre de Ximena, Juan Carlos Vicario. Darwinia encontró a Ximena en el año 1984, sin embargo, la recuperación definitiva se extendió hasta 1989. Fundadora de la filial Rosario de Abuelas de Plaza de Mayo, Darwinia integró también el grupo de Familiares de Detenidos y Desaparecidos por Razones Políticas y Gremiales de Rosario y de Madres de Plaza de Mayo delegación Rosario desde sus comienzos. Falleció el 28 de noviembre de 2008. Véase Scocco, Marianela, "La historia de una
} 
trabajar acá en Abuelas, que le ayudé a constituir todos los archivos de ese momento, porque se logra un acuerdo con la Corte, que es el que usa todavía Abuelas, y vamos a revisar todos los expedientes NN que había en los Juzgados de Menores." 59

\section{A modo de cierre}

En el contexto previo a la última dictadura militar, algunos reconocidos abogados había partido al exilio -como el doctor Juan Carlos Gardella, cesanteado por la Intervención Saráchaga que debió exiliarse en 1974 mientras que otros fueron asesinados. Tal fue el caso de los abogados Felipe Rodríguez Araya y Luis Eduardo Lescano.

Otros, sin embargo, continuaron con sus tareas en defensa de los presos políticos, ahora la mayoría de ellos en la nueva condición de asesoramiento a los familiares e intervención jurídica en los casos de desaparecidos. Se destacaron aquellos pertenecientes al Departamento Jurídico de la LADH Rosario, así como otros que participaron simultáneamente en los organismos de derechos humanos que se iban constituyendo en la ciudad, como los ejemplos de las abogadas Delia Rodríguez Araya e Inés Cozzi que hemos analizado. La circulación y pertenencia de estos abogados en más de una organizaciónfue lo habitual en la ciudad de Rosario.

Estudiar a estas actoras y los espacios asociativos de los cuales formaron parte, haciendo hincapié en la circulación de ellas en más de una organización, demuestra cómo estas trayectorias condensan la enorme transformación operada en las formas de asumir el compromiso con la causa de los derechos humanos.

Existe una extendida suposición acerca de que los motivos que incentivaron la participación de los profesionales del derecho en los organismos de derechos humanos a partir de la última dictadura militar se explican como un resultado directo y automático de la represión del Estado. Pero sin desconocer la importancia que la intensificación de la represión tuvo, consideramos que su compromiso militante con la causa también se comprende por lazos políticos, sociales y afectivos previos a la constitución de las organizaciones y por afinidades ideológicas preexistentes a la propia acción colectiva. Las vías que llevan de la defensa de los presos políticos a la participación en los organismos de derechos humanos están incorporadas a los repertorios de acciones implementadas a partir de la última dictadura militar y en los primeros años de la democracia.

\section{Bibliografía}

Alonso, Luciano, Luchas en plazas vacías de sueños.Movimiento de derechos humanos, orden local y acción antisistémica en Santa Fe, Rosario, Prohistoria Ediciones, 2011.

Alonso, Luciano, "Emergencia, auge y crisis del movimiento por los derechos humanos en Santa $\mathrm{Fe}, 1977-1989$ ", en El país del sí me acuerdo. Los orígenes nacionales y transnacionales del movimiento de derechos humanos en Argentina: De la dictadura a la transición, Red Latinoamericana de Historia Oral, Buenos Aires: Editorial Imago Mundi, 2014.

Alonso, Luciano, "El estudio de las luchas pro derechos humanos en Argentina: problemas de enfoque en torno a la categoría de movimiento social", en FLIER, Patricia (comp.) Dilemas, apuestas y reflexiones teórico metodológicas para los abordajes en Historia Reciente, La Plata, Facultad de Humanidades y Ciencias de la Educación de la Universidad Nacional de La Plata, 2014.

búsqueda. Darwinia Gallicchio, Madre y Abuela de Plaza 25 de Mayo de Rosario”, Aletehia vol. 3, nro.5, La Plata, 2012.

${ }^{59}$ Inés Cozzi. Entrevista realizada el 25 de febrero de 2016 en Rosario. 
Bereciartúa, Leticia, Abogados y defensas politicas 1968-1973, Tesina de Licenciatura, Universidad Nacional de Rosario, Mimeo, 2013.

Chama, Mauricio, "Activismo social, militancia política y radicalización en los años sesenta. La experiencia de la Comisión de Familiares y Detenidos (COFADE)", en Tortti, María Cristina (dir.) La nueva irquierda argentina (1955-1976): socialismo, peronismo y revolución, Rosario, Prohistoria Ediciones, 2014.

Chama, Mauricio, Compromiso político y labor profesional. Estudios sobre psicólogos y abogados en los primeros setenta, La Plata, Universidad Nacional de La Plata. Facultad de Humanidades y Ciencias de la Educación, 2016.

Del Frade, Carlos, Delia, la abogada militante, Rosario, Editorial La Comuna, 2011.

Lezcano, Erika, "Testigos, protagonistas y redes sociales en el proceso de surgimiento y consolidación de la Regional Rosario del Movimiento Ecuménico por los Derechos Humanos (MEDH). Primera mitad de los años '80", Seminario Regional, en Historia, Facultad de Humanidades y Artes, Universidad Nacional de Rosario, Mimeo, 2015.

Merele, Hernán, "La "depuración” ideológica del peronismo en el partido de General Sarmiento (1973 - 1974). Una aproximación a partir del caso de Antonio "Tito" Deleroni.", Tesis de Maestría en Historia Contemporánea, Universidad Nacional de General Sarmiento, Mimeo, 2015.

Scocco, Marianela: El viento sigue soplando. Los origenes de Madres de Plaza 25 de Mayo de Rosario (1977-1985), Rosario, Editorial Último Recurso, 2016.

Scocco, Marianela, "De la denuncia a la (in)justicia. Rosario: de la delegación Santa Fe de la CONADEP a los indultos (1983-1990)", Revista Argirópolis, № 1 (segundo semestre, 2015), Instituto de Estudios Históricos del Parlamento Argentino, pp. 39-60.

Scocco, Marianela, "La historia de una búsqueda. DarwiniaGallicchio, Madre y Abuela de Plaza 25 de Mayo de Rosario", Aletehia, vol. 3, nro. 5, La Plata, 2012.

Vecchioli, Virginia, "Derechos Humanos y compromiso militante. Un recorrido por la constitución de esta causa a través de los profesionales del derecho", Etnografías Contemporáneas 2 (3), 2007, pp. 143-168.

\section{Artículos periodísticos}

Basso, Juane, "Juicio Díaz Bessone: La violación de detenidas fue una práctica sistemática”, en El diario de los Juicios, Rosario, disponible en:

http:/ /www.diariodelosjuicios.com/2010/11/juicio-diaz-bessone-la-violacion-de.html.

Tessa, Sonia "Esto tiene que terminar de una vez", en Diario Rosario/12, Rosario, 30 de noviembre de 2010.

\section{Entrevistas}

Inés Cozzi. Entrevista realizada el 25 de febrero de 2016 en la Rosario. 